\title{
Water soluble biomolecules from Nepeta nuda regulate microbial growth: A case study of apple juice preservation
}

\author{
Uroš GaŠıć ${ }^{1, *, \dagger}$, Dejan Stojković ${ }^{1, \dagger}$, MariJa IVAnov ${ }^{1}$, Milica Miletić$^{2}$, DaniJela Mišıć ${ }^{1}$, \\ Milan VelJić ${ }^{2}$, ANd Marina SOKOVIć ${ }^{1}$ \\ ${ }^{1}$ Department of Plant Physiology, Institute for Biological Research "Siniša Stanković" - National Institute of Republic of Serbia, University of Belgrade, \\ Bulevar despota Stefana 142, 11060 Belgrade, Serbia \\ ${ }^{2}$ University of Belgrade - Faculty of Biology, Institute of Botany and Botanical Garden “Jevremovac", 11000 Belgrade, Serbia \\ *Corresponding author: uros.gasic@ibiss.bg.ac.rs \\ ${ }^{\dagger}$ These authors contributed equally to this work
}

Published: December 25, 2021

Received: September 4, 2021

Accepted: October 19, 2021

Published on-line: October 25, 2021

\begin{abstract}
The following study was designed to explore antimicrobial properties of the by-product obtained in a hydro-distillation process of essential oil from Nepeta nuda L. We strived to develop a novel drink with antimicrobial self-preserving properties based on two components, $N$. nuda decoct and apple juice. By using 96-well plate microdilution assay it was shown that the $N$. nuda decoct has antimicrobial potential towards 8 bacterial and 6 fungal species, with the range of minimal inhibitory concentrations 10-300 mg/mL. By using actual food system, such as apple juice, in combination with and without short thermal treatment, we have shown that the decoct of $N$. nuda can inhibit the growth of food contaminant fungus Penicillium aurantiogriseum. It was determined that 3 volumes of decoct $(500 \mathrm{mg} / \mathrm{mL}$ ) and 22 volumes of apple juice should be mixed in order to obtain self-preserving drink resistant to $P$. aurantiogriseum contamination. Likewise, when thermal treatment $\left(80{ }^{\circ} \mathrm{C}\right.$ for $\left.10 \mathrm{~s}\right)$ is included, self-preserving mixture of decoct and apple juice should be made in volume ratios 3:47, respectively. The designed product maintained the pleasant taste as determined by panelists during the sensorial evaluation. Chemical investigations (UHPLC-Orbitrap MS analysis) of N. nuda decoct showed that the most abundant compound was 1,5,9-epideoxyloganic acid $(0.410 \mathrm{mg} / \mathrm{g}$ of dried decoct). Since $N$. nuda is traditionally used as a tea, we presented the novel formulation of the drink with antimicrobial properties based on the its decoct and apple juice.
\end{abstract}

Key words: Nepeta nuda; drink; antifungal; self-preserving; chemical composition

http://dx.doi.org/10.5937/leksir2141028G

\section{INTRODUCTION}

Apple juice is one of the most widely consumed juices due to its health beneficial and nutraceutical properties accompanied by a pleasant taste. Juice quality and safe consumption rely on methods like refrigeration and addition of chemical preservatives to keep the product safe. Unfortunately, disease outbreaks, related to consumption of food contaminated with microorganisms, increased (Gayán et al., 2013). Since fruit juices of high quality and safety are current demand worldwide it is of prime importance that edibles are free of spoilage microbes (Keyser et al., 2008). Pasteurization, sterilization and addition of synthetic antimicrobials can solve this issue but also can change products' characteristics like color, aroma, and vitamin content (Heinz et al., 2003). Heat treatment and addi- tion of antimicrobial preservatives are frequently used tools to dispose of microorganisms and extend shelf life of foods and beverages (Gayán et al., 2013). However, application of artificial preservatives is associated with numerous undesirable effects (Fiolet et al., 2018). Therefore, there is a notable interest in using natural matrices as juice preservatives that would keep the product safe for use and extend its shelf-life. Majority of food spoilage is caused by yeasts, moulds species and some acid-tolerant bacteria. Soft drinks can be friendly environment for microorganisms which can grow in acidic $\mathrm{pH}$ with low concentration of oxygen (Wareing and Davenport, 2004). The most frequently found yeasts and moulds species responsible for the juice spoilage are Pichia sp., Candida sp., Saccharomyces sp., and Rhodotorula sp. for yeasts and Penicillium sp., Cladosporium sp., Aspergillus niger, A. fumigatus, Botrytis 
sp., and Aureobasidium pullulans for moulds (Aneja et al., 2014). Considering that in our previous work (Reis et al., 2012) Penicillium aurantiogriseum was isolated from contaminated food, it was chosen as representative strain of spoilage fungi to test antimicrobial self-preserving properties of newly designed drink based on Nepeta nuda L. decoct and apple juice.

The genus Nepeta L. includes approximately 300 species and represents one of the largest genera in the Lamiaceae family, subfamily Nepetoideae. Nepeta species are mostly perennial, rarely annual plants (Asgarpanah et al., 2014), and are native to Europe, Asia, North Africa and North America with the greatest richness in Southwest Asia (mainly Iran) and Western Himalayas (Nargis Jamila, 2011; Süntar et al., 2018). Some species from this genus are used as food flavouring agents, including N. ispahanica, N. binaloudensis, N. bracteata, N. pogonosperma, N. pungens and N. crispa (Nargis Jamila, 2011; Süntar et al., 2018). There are different classes of bioactive compounds in Nepeta species, predominated by terpenes and phenolic acids (Salehi et al., 2018; Süntar et al., 2018). The majority of bioactive properties are ascribed to iridoid monoterpenoids nepetalactones, unique group of compounds for this group of plants (Süntar et al., 2018). Although abundant in Nepeta species, iridoid glucosides are largely neglected and their bioactivity has been scarcely investigated. Only recently, it has been demonstrated that the dominant iridoid glucoside in Nepeta species, 1,5,9-epideoxyloganic acid, is as equally potent antimicrobial as nepetalactones (Aničić et al., 2021). Being present as a glucoside this compound is less volatile than nepetalctones, and is thus more stable in food formulations.

The aim of the present study was to utilize Nepeta nuda decoct, by-product obtained during the distillation process of $N$. nuda essential oil, which is a rich source of 1,5,9-epideoxyloganic acid, to preserve apple juice. The idea was to extend shelf life and maintain quality of the juice without using chemical preservatives, while keeping organoleptic characteristics. Therefore, the aim of this work was to phytochemically characterize N. nuda decoct and investigate its in vitro antibacterial and antifungal activities. Additionally, the objective was to analyze the self-preserving potential of $N$. nuda decoct in blended apple juice on the growth of Penicillium verrucosum var. cyclopium in combination with thermal treatment. Literature survey revealed that that Nepeta nuda decoct is traditionally used internally against cystitis and prostate gland inflammation and externally for wound healing (Kozuharova et al., 2014) and also as a herbal tea for treating hysteria, melancholy and uterine cramps (Aćimović et al., 2020).

\section{MATERIALS AND METHODS}

\subsection{Plant material and by-product of $N$. nuda essential oil distillation}

The samples of wild growing Nepeta nuda L. were collected from mountain Tara, Serbia, in summer 2013, and authenticated by Dr. Milan Veljić (Faculty of Biology, University of Belgrade). The samples were lyophilized (LH Leybold, Lyovac GT2, Frenkendorf), reduced to a fine dried powder and stored in a desiccator, protected from light, until further analysis.

During essential oil hydro-distillation (for $3 \mathrm{~h}$ ) according to Gormez et al. (2013) in a Clevenger type apparatus a byproduct from N. nuda was obtained. Boiled water containing $N$. nuda sample from hydro-distillation process was filtered (Whatman No 4) after cooling, and further frozen at $-20{ }^{\circ} \mathrm{C}$. Sample was subsequently lyophilized (LH Leybold, Lyovac GT2, Frenkendorf) until dryness. Dried decoct obtained as described above was used for all further investigations.

\subsection{Microorganism}

The antibacterial activity of N. nuda decoct was tested against eight bacteria species: Gram-positive Bacillus cereus (clinical isolate), Listeria monocytogenes (NCTC 7973), Micrococcus flavus (ATCC 10240) and Staphylococcus aureus (ATCC 6538) bacteria as well as Gram-negative Enterobacter cloacae (clinical isolate), Escherichia coli (ATCC 35218), Pseudomonas aeruginosa (ATCC 27853) and Salmonella typhimurium (ATCC 13311).

The antifungal activity of $N$. nuda decoct was tested against eight fungi: Aspergillus fumigatus (ATCC 1022), A. niger (ATCC 6275), A. versicolor (ATCC 11730), A. ochraceus (ATCC 12066), P. funiculosum (ATCC 8725), P. ochrochloron (ATCC 9112), P. aurantiogriseum (food isolate), and Trichoderma viride (IAM 5061).

All of the microorganisms were deposited at the Mycological Laboratory, Institute for Biological Research "Siniša Stanković", University of Belgrade, Serbia.

\subsection{Antibacterial activity}

The antibacterial assay was done by microdilution method (CLSI, 2015; Tsukatani et al., 2012) utilizing 96-well microtiter plates to determine the minimum inhibitory concentration (MIC) and minimum bactericidal concentration (MBC). The bacterial suspensions were adjusted with sterile saline solution until the concentration of $1.0 \times 10^{8} \mathrm{CFU} / \mathrm{mL}$. N. nuda decoct was dissolved in sterile distilled water and added to Tryptic Soya Broth medium and after inoculated with bacteria in final concentration $1 \times 10^{6} \mathrm{CFU} /$ well $(100 \mu \mathrm{L})$. The microplates were incubated for $24 \mathrm{~h}$, at $37^{\circ} \mathrm{C}$. The lowest concentrations without visible growth of bacteria under the optical microscope were defined as the minimum inhibitory concentrations (MICs). Furthermore, the MICs of the samples were detected following the addition of $40 \mu \mathrm{L}$ of iodonitrotetrazolium chloride (INT) $(0.2 \mathrm{mg} / \mathrm{mL})$ and incubation at $37^{\circ} \mathrm{C}$ for $30 \mathrm{~min}$. The lowest concentration that produced a significant inhibition (around $50 \%$ ) of the growth of the bacteria in comparison with the positive control was identified as the MIC. MICs, obtained from the susceptibility testing of various bacteria to tested extracts were determined also by a colorimetric microbial viability assay based on the reduction of the INT color and compared with a positive control for each bacterial strain. $\mathrm{MBC}$ was determined by serial sub-cultivation of $2 \mu \mathrm{L}$ into microplates containing $100 \mu \mathrm{L}$ of TSB. The lowest concentration that showed no growth after this sub-culturing was read as the MBC. The results were expressed in $\mathrm{mg} / \mathrm{mL}$. Sodium benzoate (E211) was utilized as positive control $(1 \mathrm{mg} / \mathrm{mL}$ in sterile saline solution). Sterile distilled water was used as negative control.

\subsection{Antifungal activity}

A modified microdilution technique was utilized to investigate the antifungal activity (Daouk et al., 1995; Espinel-Ingroff, 2001). The fungal spores were washed with sterile saline solution at $0.85 \%$ containing polysorbate- $80(0.1 \%)$. The spore suspension was adjusted with sterile saline solution to a concentration of $1.0 \times 10^{5}$ in a final volume of $100 \mu \mathrm{L}$ per well. The inoculums were stored at $4{ }^{\circ} \mathrm{C}$ for posterior utilization. The inoculum dilutions were cultivated in malt extract agar to verify the absence of contamination and validate each inoculum.

MIC was determined by serial dilution technique using 96well microtiter plates. Dissolved decoct of N. nuda was added to a malt extract broth with fungal inoculum. The microplates were incubated for $72 \mathrm{~h}$ at $28^{\circ} \mathrm{C}$. The lowest concentrations without visible microbial biomass growth under optical microscope were defined as the concentrations that completely inhibited fungal growth. 
Minimum fungicidal concentration (MFC) was determined by a $2 \mu \mathrm{L}$ serial sub cultivation of the tested compound dissolved in a cultivation medium, and inoculated during $72 \mathrm{~h}$ in microtiter plates containing $100 \mu \mathrm{L}$ of broth per well and with incubation for $72 \mathrm{~h}$ at $28^{\circ} \mathrm{C}$. The lowest concentration without visible biomass concentration was defined as MFC indicating the death of $99.5 \%$ of the original. The commercial fungicide bifonazole (Srbolek, Belgrade, Serbia) was used as positive control $(1-3500 \mu \mathrm{g} / \mathrm{mL})$.

\subsection{In situ self-preservation of formulated drink \\ 2.5.1. Apple juice}

Apples (Granny Smith) were purchased on the local market. Apple was cleansed in alcohol after which skin was peeled off and seeds were discarded. Juice was prepared in a sterile blender (10 g of apples and $100 \mathrm{~mL}$ of sterile water), filtered through filter paper and centrifuged. Supernatant was used as apple juice. $\mathrm{pH}$ of the juice was measured and was 3.5 The apple juice obtained in such manner was cultivated on laboratory broths to check the absence of contamination with bacteria or fungi.

\subsubsection{Formulation of effective antifungal concentration of $N$. nuda decoct in apple juice combined with thermal treatment}

N. nuda decoct was dissolved in sterile distilled water (500 $\mathrm{mg} / \mathrm{mL}$ ) and combined with apple juice in different ratios to explore the most effective concentration. Firstly, MIC and MFC concentrations of $N$. nuda decoct (in prepared apple juice used as medium base) were determined as described previously in the section 2.4. Furthermore, apple juice was used solely to investigate fungal growth with $P$. aurantiogriseum (1 $\times 10^{5} \mathrm{CFU} / \mathrm{mL}$ ) used as contaminant species. It was determined that the fungus grew and sporulated in apple juice. The volume ratios of $N$. nuda decoct $(500 \mathrm{mg} / \mathrm{mL})$ and apple juices used in the experiment were as follows 48:52, 24:76, 12:88, 6:94 and 3:97. The experimental flasks were kept at room temperatures for 5 days. After determination of MIC and MFC in this self-preserving system, it was further explored if heat pasteurization (at $80^{\circ} \mathrm{C}$ in water bath for $10 \mathrm{~s}$ and $30 \mathrm{~s}$ ) of the inoculated mixtures may reduce MIC and MFC concentrations for $P$. aurantiogriseum. MIC and MFC concentrations of $N$. nuda decoct were determined in all of the experimental conditions, as well as volume ratios of $N$. nuda decoct (500 $\mathrm{mg} / \mathrm{mL}$ ) and apple juice necessary for self-preservation under different conditions (with or without thermal treatment).

\subsubsection{Sensory evaluation}

Sensory evaluation of apple juice mixed with NND (as described in the section 2.5. for the final formulation) was assessed by a group of 10 untrained panellists. Panellists were selected among students and staff of the Institute for Biological Research "Sinisa Stankovic" - National Institute of Republic of Serbia, University of Belgrade. The panellists were asked to evaluate overall acceptance of the drink sample on a scale from 5 to 1 ; indicating decreasing taste. Overall acceptance was evaluated using a 5-point scale, according to a previous report, where 1 = extremely dislike, 2 = dislike, 3 = neither like nor dislike, $4=$ like; $5=$ extremely like. Results were expressed as average grades given by 10 panellists.

\subsection{Chemical characterization of $N$. nuda decoct \\ 2.6.1. UHPLC-Orbitrap MS analysis}

Dried N. nuda decoct was diluted in $96 \%$ methanol (w:v=1:10) and extracted in an ultrasonic bath for $10 \mathrm{~min}$. Following 10 min centrifugation at $10,000 \mathrm{~g}$ supernatant was filtered through $0.2 \mu \mathrm{m}$ cellulose filters (Agilent Technologies, Santa Clara, CA) and stored at $4{ }^{\circ} \mathrm{C}$ until use.
Chemical characterization of $N$. nuda decoct was performed using ultra-high performance liquid chromatographic (UHPLC) system consisting of a quaternary Accela 600 pump, Accela Autosampler (ThermoFisher Scientific, Bremen, Germany). Syncronis C18 $(100 \times 2.1 \mathrm{~mm}, 1.7 \mu \mathrm{m}$ particle size $)$ at $40{ }^{\circ} \mathrm{C}$ was used as analytical column for separation. The mobile phase consisted of (A) water with $0.1 \%$ formic acid in ultrapure water and (B) acetonitrile with $0.1 \%$ formic acid. The linear gradient program was used: $0.0-1.0 \mathrm{~min} 5 \% \mathrm{~B}, 1.0$ $16.0 \mathrm{~min}$ from $5 \%$ to $95 \%$ (B), 16.0-16.1 $\mathrm{min}$ from $95 \%$ to 5 $\%$ (B), then $5 \%$ (B) for 4 min (Vasić et al., 2019). The injection volume for all samples was $5 \mu \mathrm{L}$ and the flow rate was 0.3 $\mathrm{mL} / \mathrm{min}$.

UHPLC system was coupled to a linear ion trap - OrbiTrap hybrid mass spectrometer (LTQ OrbiTrap MS) equipped with heated electrospray ionization probe (HESI-II; Thermo Fisher Scientific, Bremen, Germany). The mass spectrometer operated in negative ion mode and MS spectra were acquired by full range acquisition covering $100-1000 \mathrm{~m} / \mathrm{z}$. Parameters of the ion source was as in Gašić et al. (2015). Resolution was set at 30,000 for full scan analysis. The data-dependent MS/MS events were always performed on the most intense ions detected in the full scan MS. The ions of interest were isolated in the ion trap with an isolation width of $5 \mathrm{ppm}$ and activated with $35 \%$ collision energy levels (CEL).

Xcalibur software (version 2.1) was used for instrument control, data acquisition and data analysis. The molecule editor program, ChemDraw (version 12.0), was used as a reference library to calculate the exact (monoisotopic) masses of compounds of interest. The tentative identification of compounds for which standards are not available was achieved using previously reported MS fragmentation data found in literature.

\subsubsection{UHPLC/-HESI-MS/MS quantitative analysis}

Quantitative analysis was performed using Dionex Ultimate 3000 UHPLC system (Thermo Fisher Scientific, Germany) connected to TSQ Quantum Access Max triple-quadrupole mass spectrometer (Thermo Fisher Scientific, Switzerland), operating in a negative ionization mode. Chromatographic separation of nine targeted compounds in N. nuda samples was performed at $30{ }^{\circ} \mathrm{C}$ on Hypersil gold C18 column $(50 \times 2.1$ $\mathrm{mm}$ ) with $1.9 \mathrm{~m}$ particle size (Thermo Fisher Scientific, USA). Mobile phases, gradient elution program and the settings of mass spectrometer were previously described in Mišić et al. (2015). Selected reaction monitoring (SRM) mode of the mass spectrometer was utilised for the quantitative analysis, with collision-induced fragmentations performed using argon, and collision energy ( $\mathrm{cE}$ ) set to $30 \mathrm{eV}$. Xcalibur software (version 2.2) was used for the instrument control, data acquisition, and analysis.

Compounds were quantified based on the calibration curves of commercial standards: caffeic acid, rosmarinic acid and quercetin, all purchased from Sigma Aldrich (Steinheim, Germany). Regression was calculated for the calibration curves, and they all showed good linearity $(r=0.999, \mathrm{P}<0.001)$. The total amount of each targeted compound was evaluated by the calculation of peak areas and is expressed as $\mu \mathrm{g}$ per $\mathrm{g}$ of dry weight $(\mu \mathrm{g} / \mathrm{g} \mathrm{dw})$. Nepetanudoside, tuberonic acid glucoside, 1,5,9-epideoxyloganic acid, and caffeoylglycolic acid were quantified relatively, using the calibration curve of rosmarinic acid.

\section{RESULTS AND DISCUSSION}

\subsection{Antimicrobial activity}

The results of antibacterial activity are presented in the Table 1. Escherichia coli and Pseudomonas aeruginosa were the most resistant species of bacteria to inhibitory potential of Nepeta 
nuda decoct with MIC of $20 \mathrm{mg} / \mathrm{mL}$ and MBC of $40 \mathrm{mg} / \mathrm{mL}$. The other investigated species of bacteria such as Micrococcus flavus, Salmonella typhimurium, Enterobacter cloacae, Listeria monocytogenes, Staphylococcus aureus and Bacillus cereus showed the same reaction to inhibitory and bactericidal effect of the N. nuda decoct (MIC $10 \mathrm{mg} / \mathrm{mL}$; MBC $20 \mathrm{mg} / \mathrm{mL}$ ). From the results given above, it is evident that the antibacterial effect was not related with the difference in cell wall of G+ and Gbacteria, but the effect was dependent on the bacteria used for the investigation. Regarding positive control - E211, the antibacterial effect was stronger when compared with the effect of N. nuda decoct. This was expected as well, since the commercial preservative represents one single active compound, while decoct is a mixture of different compounds that might exhibit synergistic or even antagonistic effects.

Table 1. Antimicrobial activity of Nepeta nuda decoct in $\mathrm{mg} / \mathrm{mL}$.

\begin{tabular}{lrrrrrr}
\hline & \multicolumn{2}{c}{$\mathrm{NND}^{\mathrm{a}, \mathrm{b}}$} & & \multicolumn{2}{c}{ E211 } \\
\cline { 2 - 3 } \cline { 6 - 7 } Fungal/bacterial strain & MIC & MBC & & MIC & MBC \\
\hline Micrococcus flavus & 10 & 20 & & 2 & 4 \\
Salmonella typhimurium & 10 & 20 & & 1 & 2 \\
Escherichia coli & 40 & 80 & & 1 & 2 \\
Enterobacter cloacae & 10 & 20 & & 2 & 4 \\
Pseudomonas aeruginosa & 40 & 80 & & 1 & 2 \\
Listeria monocytogenes & 10 & 20 & & 1 & 2 \\
Staphylococcus aureus & 10 & 20 & & 4 & 4 \\
Bacillus cereus & 10 & 20 & & 0.5 & 0.5 \\
Aspergillus flavus & 150 & 300 & & 1 & 2 \\
Aspergillus niger & 300 & $>300$ & & 1 & 2 \\
Penicillium funiculosum & 37.5 & 75 & & 1 & 2 \\
Penicillium aurantiogriseum & 37.5 & 75 & & 2 & 4 \\
Aspergillus versicolor & 150 & 300 & & 2 & 2 \\
Penicillium ochrochloron & 300 & $>300$ & & 1 & 2 \\
\hline
\end{tabular}

${ }^{a}$ NND stands for Nepeta nuda decoct

${ }^{\mathrm{b}} \mathrm{MIC}$ and MBC stand for Minimum Inhibitory and Minimum Bactericidal Concentration, respectively.

c E211 - sodium benzoate was utilized as positive control.

Regarding antifungal activity of the investigated decoct, the results are presented in the Table 1 . The most sensitive microfungi to decoct antifungal effect were Penicillium funiculosum and Penicillium aurantiogriseum with MIC of $37.5 \mathrm{mg} / \mathrm{mL}$ and MFC of $75 \mathrm{mg} / \mathrm{mL}$. Aspergillus niger was the most resistant fungal strain to which antifungal effect was not recorded up to $300 \mathrm{mg} / \mathrm{mL}$. Antifungal effect of the commercial drug bifonazole was prominent when compared to decoct antifungal effect, as expected.

Although the antimicrobial effects were less pronounced than those recorded for commercial preservatives, $N$. nuda showed an interesting antimicrobial potential, which might be exploited to protect apple juice from spoilage. As decoct is the by-product of essential oil distillation, and is usually discarded, the present study offers the new perspective to rationally utilize the plant material, in a cost-effective way. To our best knowledge this is the first report on the antimicrobial activity of $N$. nuda decoct. There is only some information about antimicrobial activity of N. nuda essential oil (Gormez et al., 2013) and tincture (Smiljković et al., 2018).

\subsection{Self-preserving properties of newly designed drink and sensory evaluation}

Penicillium aurantiogriseum is able to contaminate apple juice, and at the same time was one of the two most sensitive fungal species to Nepeta nuda decoct (NND). This strain was used as a model system for the formulation of self-preserving drink based on NND and apple juice. Firstly, we have established effective inhibitory and fungicidal concentrations of NND in apple juice as a medium. It was shown that MIC and MFC were higher when compared to the in vitro experiment, suggesting that apple juice is more complex medium than simple laboratory broth used for in vitro experiment. MIC was determined at $60 \mathrm{mg}$ NND/mL of apple juice and MFC at $120 \mathrm{mg}$ $\mathrm{NND} / \mathrm{mL}$ of apple juice. Therefore, we were able to formulate volume ratios of NND (500 mg/mL) and apple juice (prepared as described in Material and Methods section) (Table 2).

Table 2. MIC, MFC $[\mathrm{mg} / \mathrm{mL}]$ of $N$. nuda decoct (NND) and volume ratios of NND and apple juice after 5 days incubation of P. aurantiogriseum without or with heat pasteurization $\left(80^{\circ} \mathrm{C}\right)$.

\begin{tabular}{|c|c|c|c|c|}
\hline & $\mathrm{MIC}^{\mathrm{a}}$ & $\begin{array}{r}\text { Volume } \\
\text { ratio }\end{array}$ & $\mathrm{MFC}^{\mathrm{b}}$ & $\begin{array}{r}\text { Volume } \\
\text { ratio }\end{array}$ \\
\hline $\mathrm{NND}^{\mathrm{c}}$ & 60 & $6: 94$ & 120 & $12: 88$ \\
\hline NND (10 s) & 30 & 3:97 & 60 & $6: 94$ \\
\hline NND (30 s) & 30 & 3:97 & 60 & $6: 94$ \\
\hline
\end{tabular}

a MIC stands for Minimum Inhibitory Concentration.

${ }^{\mathrm{b}}$ MFC stand for Minimum Fungicidal Concentration.

${ }^{c}$ NND stands for Nepeta nuda decoct

In the light of that fact, 3 volumes of NND $(500 \mathrm{mg} / \mathrm{mL})$ and 22 volumes of apple juice should be mixed in order to obtain self-preserving drink resistant to $P$. aurantiogriseum contamination. Furthermore, we investigated how the short thermal treatment would influence the antifungal effect of NND (Table 2). There were no significant differences between thermal treatments for $10 \mathrm{~s}$ and $30 \mathrm{~s}$. The short thermal treatment at 80 ${ }^{\circ} \mathrm{C}$ for $10 \mathrm{~s}$ was the best choice in order to enhance fungicidal properties of NND and lower its amount in the final mixture. The final formulation of self-preserving mixture of NND and apple juice should be made in volume ratios 3 (NND): 47 (apple juice) and thermally treated at $80^{\circ} \mathrm{C}$ for $10 \mathrm{~s}$, in order to have the best effect against $P$. aurantiogriseum contamination. Since Nepeta nuda is used as a tea in some traditional medicines (Sharma et al., 2021), together with some other Nepeta species, we considered it appropriate for combination with apple juice to make a novel drink with functional properties. Furthermore we have investigated overall acceptability of the newly designed drink formulation as described above for the final formulation. The results for sensorial evaluation indicated that overall acceptability of the drink was high with average grade 4.4 suggesting that the product was likable for the panelists.

\subsection{Chemical composition of $\boldsymbol{N}$. nuda decoct}

To determine major bioactive principles, LC/MS characterization of N. nuda decoct was performed and it resulted in the detection of nine compounds. Among identified compounds, three were confirmed using available standards (caffeic acid, rosmarinic acid, and quercetin), while the others were identified using high resolution mass spectrometry (HRMS) with multi stage mass spectrometry (MSn). The base peak chromatogram of $N$. nuda decoct is presented in Figure 1. The main LC/MS data of identified compounds are summarized in Table 3.

Compounds 1 and 4 with pseudomolecular ion $\left([\mathrm{M}+\mathrm{HCOOH}-\mathrm{H}]^{-}\right)$at $435 \mathrm{~m} / \mathrm{z}$ were marked as two isomers of nepetanudoside. In the first stage of fragmentation, formic acid ( $\mathrm{HCOOH}, 46 \mathrm{Da})$ is lost, which, in this case, was an adduct bound to the molecular ion. Thus a fragment 
Table 3. Tentative identification of the compounds in N. nuda decoct.

\begin{tabular}{|c|c|c|c|c|c|c|c|c|c|}
\hline $\begin{array}{l}\text { Peak }^{\mathrm{a}} \\
\text { No. }\end{array}$ & $\begin{array}{l}t_{R}^{b} \\
\min \end{array}$ & Compound name & $\begin{array}{l}\text { Molecular formula } \\
\qquad[\mathrm{M}-\mathrm{H}]^{-}[\mathrm{m} / \mathrm{z}]\end{array}$ & $\begin{array}{l}\text { Calculated mass } \\
{[\mathrm{M}-\mathrm{H}]^{-}[\mathrm{m} / \mathrm{z}]}\end{array}$ & $\begin{array}{r}\text { Exact mass } \\
{[\mathrm{M}-\mathrm{H}]^{-}[\mathrm{m} / \mathrm{z}]}\end{array}$ & $\Delta \mathrm{ppm}^{\mathrm{c}}$ & $\begin{array}{r}\text { MS}^{2} \text { Fragments } \\
{[\mathrm{m} / \mathrm{z}](\% \text { Base Peak })}\end{array}$ & $\begin{array}{r}\mathrm{MS}^{3} \text { Fragments } \\
{[\mathrm{m} / \mathrm{z}](\% \text { Base Peak })}\end{array}$ & $\begin{array}{r}\mathrm{MS}^{4} \text { Fragments } \\
{[\mathrm{m} / \mathrm{z}](\% \text { Base Peak) }}\end{array}$ \\
\hline 1 & 5.45 & Nepetanudoside isomer $+\mathrm{HCOOH}$ & $\mathrm{C}_{18} \mathrm{H}_{27} \mathrm{O}_{12}-$ & 435.1508 & 435.15026 & 1.24 & 225(5), 227(100), 228(10), 365(5), 387(5), 389(5) & 101(100), 127(10), 209(5) & - \\
\hline 2 & 5.66 & Tuberonic acid glucoside & $\mathrm{C}_{18} \mathrm{H}_{27} \mathrm{O}_{9^{-}}$ & 387.16606 & 387.16563 & 1.10 & 163(55), 207(100), 318(15), 321(10), 341(15), 369(15) & $163(100)$ & - \\
\hline 3 & 5.75 & Caffeic acid ${ }^{d}$ & $\mathrm{C}_{9} \mathrm{H}_{7} \mathrm{O}_{4}^{-}$ & 179.03498 & 179.03471 & 1.51 & $135(100)$ & 135(60), 117(15), 107(100), 91(55), 79(15) & - \\
\hline 4 & 5.79 & Nepetanudoside & $\mathrm{C}_{18} \mathrm{H}_{27} \mathrm{O}_{9-}$ & 435.1508 & 435.15051 & 0.66 & 227(100), 228(15), 388(30), 389(65), 390(10) & 69(5), 101(100) & - \\
\hline 5 & 6.16 & 1,5,9-Epideoxyloganic acid & $\mathrm{C}_{16} \mathrm{H}_{23} \mathrm{O}_{9-}$ & 359.13476 & 359.13461 & 0.42 & 197(100), 153(65), 135(20), 109(15) & 153(100), 135(10), 109(30) & 135(100) \\
\hline 6 & 6.40 & 1,5,9-Epideoxyloganic acid isomer & $\mathrm{C}_{16} \mathrm{H}_{23} \mathrm{O}_{9-}$ & 359.13476 & 359.13449 & 0.75 & 197(100), 153(20), 135(20) & 153(100), 135(5), 109(20) & - \\
\hline 7 & 6.73 & Caffeoylglycolic acid & $\mathrm{C}_{11} \mathrm{H}_{9} \mathrm{O}_{6^{-}}$ & 237.04046 & 237.04044 & 0.08 & 209(5), 193(5), 191(20), 161(100) & 133(100), 105(10) & - \\
\hline 8 & 7.46 & Rosmarinic acid $^{\mathrm{d}}$ & $\mathrm{C}_{18} \mathrm{H}_{15} \mathrm{O}_{8^{-}}$ & 359.07724 & 359.07648 & 2.12 & $223(10), 197(30), 179(40), 161(100), 133(10)$ & $133(100)$ & 105(100) \\
\hline 9 & 8.74 & Quercetin $^{\mathrm{d}}$ & $\mathrm{C}_{15} \mathrm{H}_{9} \mathrm{O}_{7^{-}}$ & 301.03538 & 301.03531 & 0.23 & 271(50), 255(20), 179(100), 151(80), 107(5) & $151(100)$ & 107(100), 83(10) \\
\hline
\end{tabular}

${ }^{a}$ Number of peaks (\#) which corresponds to the peak numbers on Figure 1.

${ }^{b} t_{R}-$ retention time.

${ }^{\mathrm{c}} \Delta \mathrm{ppm}-$ mean mass accuracy

${ }^{\mathrm{d} C}$ Compounds confirmed using available standards.

Table 4. UHPLC $/( \pm)$ HESI-MS ${ }^{2}$ quantification of targeted compounds in by-product of Nepeta nuda essential oil distillation. Relative intensities of the main diagnostic MS ${ }^{2}$ fragments utilized in SRM (Selected Reaction Monitoring)

\begin{tabular}{lrlrrr}
\hline $\begin{array}{l}\text { Peak }^{\mathrm{a}} \\
\text { No }\end{array}$ & $\begin{array}{r}\mathrm{t}_{\mathrm{R}}{ }^{\mathrm{b}}, \\
\mathrm{min}\end{array}$ & $\begin{array}{l}\text { Compound name } \\
{[\mathrm{M}-\mathrm{H}]^{-}} \\
{[\mathrm{m} / \mathrm{z}]}\end{array}$ & $\begin{array}{r}\mathrm{MS}^{2} \text { fragments, } \\
{[\mathrm{m} / \mathrm{z}](\% \text { Base Peak })}\end{array}$ & $\begin{array}{r}\text { Concentration } \\
{[\mu \mathrm{g} / \mathrm{g} \mathrm{dw}]}\end{array}$ \\
\hline 1 & 2.45 & Nepetanudoside isomer $+\mathrm{HCOOH}$ & 435 & $398(5), 227(100)$ & $156.41 \pm 8.74$ \\
2 & 2.55 & Tuberonic acid glucoside & 387 & $163(50), 207(100)$ & $161.51 \pm 9.03$ \\
3 & 2.60 & Caffeic acid & 179 & $135(100), 134(85)$ & $226.44 \pm 15.15$ \\
4 & 2.61 & Nepetanudoside & 435 & $398(50), 227(100)$ & $1265.48 \pm 70.74$ \\
5 & 3.39 & $1,5,9-$-Epideoxyloganic acid & 359 & $197(20), 153(100)$ & $409.87 \pm 6.22$ \\
6 & 4.07 & 1,5,9-Epideoxyloganic acid isomer & 359 & $197(100), 153(10)$ & $113.76 \pm 3.12$ \\
7 & 4.10 & Caffeoylglycolic acid & 237 & $161(50), 133(25)$ & $185.88 \pm 5.46$ \\
8 & 4.19 & Rosmarinic acid & 359 & $161(100), 133(25)$ & $272.08 \pm 15.21$ \\
9 & 4.78 & Quercetin & 301 & $179(<5), 151(100)$ & $3.54 \pm 0.07$ \\
\hline
\end{tabular}

${ }^{a}$ Number of peaks (\#) which corresponds to the peak numbers on Figure 1.

$\mathrm{b}_{\mathrm{t}_{\mathrm{R}}}$ - retention time. 


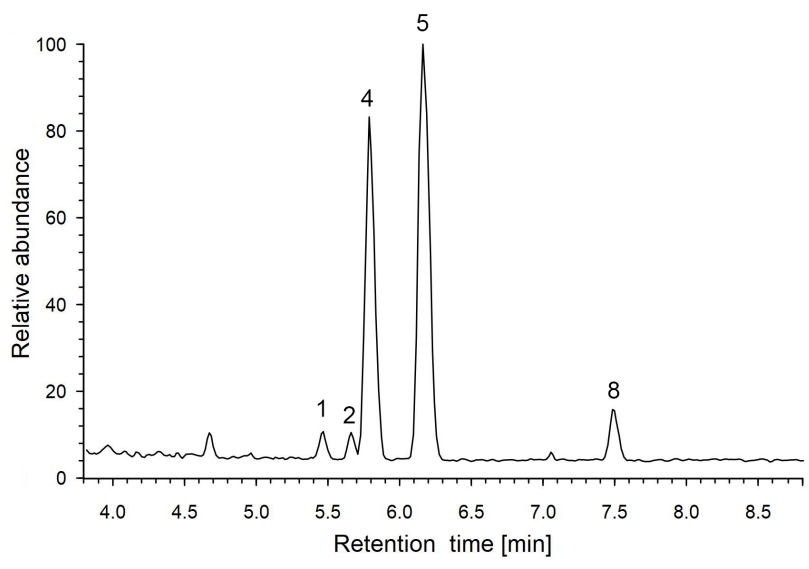

Fig. 1. UPLC/Orbitrap MS base peak chromatogram of N. nuda decoct.

is formed at $389 \mathrm{~m} / \mathrm{z}$, which corresponds to the mass of nepatanudoside. However, the most intense ion $\left(\mathrm{MS}^{2}\right.$ base peak) found at $227 \mathrm{~m} / z$, was generated by further loss of hexosyl residue (162 Da). This iridoid, nepetanudoside, got its name from the fact that it was isolated for the first time from the aerial part of Nepeta nuda ssp. albiflora (Takeda et al., 1995). Tuberonic acid glucoside (compound 2) found at $387 \mathrm{~m} / \mathrm{z}$ showed MS ${ }^{2}$ base peak at $207 \mathrm{~m} / z$ (loss of hexose, $180 \mathrm{Da}$ ). MS $^{3}$ base peak was found at $163 \mathrm{~m} / z$, generated by the loss of $\mathrm{CO}_{2}(44 \mathrm{Da})$. This compound was already identified in the extract of Calamintha nepeta (L.) Savi (Pacifico et al., 2015). The same reference explains the MS fragmentation pathway of this compound, which is fully consistent with our conclusions.

Compound 5 eluting at $6.16 \mathrm{~min}$ and displaying pseudomolekular ion $[\mathrm{M}-\mathrm{H}]^{-}$at $359 \mathrm{~m} / z$ with $\mathrm{MS}^{2}$ base peak at $197 \mathrm{~m} / \mathrm{z}$ (loss of hexosyl group - $162 \mathrm{Da}$ ) was identified as 1,5,9-epideoxyloganic acid (Table 4). The $\mathrm{MS}^{3}$ fragmentation showed base peak at $153 \mathrm{~m} / \mathrm{z}$ obtained by loss of $\mathrm{CO}_{2}$ group (44 Da), while the $\mathrm{MS}^{3}$ secondary peak at $109 \mathrm{~m} / \mathrm{z}$ was formed by further of $\mathrm{CO}_{2}$. The MS ${ }^{4}$ spectrum showed fragment ion at $135 \mathrm{~m} / z$, formed by elimination of water (18 Da) from $\mathrm{MS}^{3}$ base peak $153 \mathrm{~m} / \mathrm{z}$. Compound 6 at $6.40 \mathrm{~min}$ showing very similar MS fragmentation data was identified as an isomer of compound 5. Proposed fragmentation pathway of these two compounds is in accordance with the literature data (Aničić et al., 2021; Li et al., 2018). 1,5,9-epideoxyloganic acid is known to be present in the plants belonging to the genus Nepeta (Aničić et al., 2021; Takeda et al., 1996), and it was already identified in the N. nuda acetone extract (Dienaite et al., 2018).

Compound 7 eluting at $7.20 \mathrm{~min}$, with molecular ion $[\mathrm{M}-\mathrm{H}]^{-}$ at $237 \mathrm{~m} / \mathrm{z}$, and $\mathrm{MS}^{2}$ base peak at $161 \mathrm{~m} / \mathrm{z}$, was tentatively identified as caffeoylglycolic acid. It gave $\mathrm{MS}^{3}$ base peak at $133 \mathrm{~m} / \mathrm{z}$, generated by the loss of $\mathrm{CO}_{2}(28 \mathrm{Da})$. Proposed fragmentation pathway of compound 7 is depicted in Figure 2. This compound was already isolated and identified in Nepeta cataria (Snook et al., 1993).

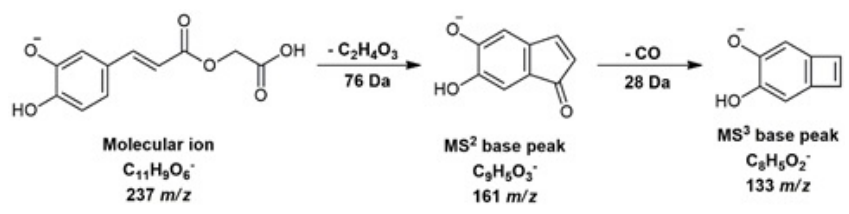

Fig. 2. Proposed fragmentation pathway of compound 7.

UHPLC/(-)HESI-MS ${ }^{2}$ quantitative analysis (Table 4) revealed that the major constituent in N. nuda decoct was nepetanudoside (compound 4 ) with concentration of $\sim 1250 \mu \mathrm{g} / \mathrm{g}$ ros- marinic acid eqivalents per $\mathrm{g} d w$. The concentration of 1,5,9epideoxyloganic acid (5), was $\sim 410 \mu \mathrm{g} / \mathrm{g} \mathrm{dw}$. Rosmarinic (8) and caffeic acid (3) were also present in significant amounts, around 272 and $226 \mu \mathrm{g} / \mathrm{g} \mathrm{dw}$, respectively. The other compounds were less abundant. Caffeic acid, rosmarinic acid and quercetin have previously been recorded in $N$. nuda leaves (Aras et al., 2016). Caffeoylglycolic acid is here reported for the first time in N. nuda.

Iridoid glucosides and phenolic acids which predominate the bioactive compounds pool of the N. nuda decoct, obviously provide the preservative properties to apple juice formulated within the present study. Some of the identified constituents have previously been highlighted as the potent antimicrobials, including 1,5,9-epideoxyloganic acid (Aničić et al., 2021), rosmarinic acid (Aničić et al., 2021; Nadeem et al., 2019), caffeic acid (Magnani et al., 2014), and quercetin (Batiha et al., 2020). Thus, each constituent of decoct alone, and the interaction of the individual decoct components (e.g. antagonistic, synergistic, additive) with the constituents of the apple juice, contribute to the overall self-preserving properties of product. Apple juice is a rich source of natural oxidants itself, and the addition of $N$. nuda decoct enriches the phenolic acids pool and, most importantly, supplies the source of iridoid glucosides which offer a new perspective to the preservation and prolongation of the shelf-life without using synthetic preservatives. Besides antimicrobial protection, decoct constituents might also improve the antioxidant properties to the apple juice, thus giving the additional value to quality and healthbenefits of the product.

\section{CONCLUSION}

Nowadays customers are more and more seeking for the beverages based on natural products without the artificial additives. In this study we have developed drink based on Nepeta nuda decoct and apple juice that is able to self-preserve. This formulation could provide the customers with drink that is resistant to P. aurantiogriseum contamination which confirmed our hypothesis.

\section{ACKNOWLEDGMENTS}

This research was funded by the Serbian Ministry of Education, Science and Technological Development (Contract numbers 451-03-9/2021-14/200007 and 451-03-9/2021-14/200042).

\section{REFERENCES}

Aćimović, M., Stanković-Jeremić, J. and Cvetković, M. (2020). Phytopharmacological aspects of Nepeta nuda L.: A systematic review, Lekovite sirovine 40: 75-83.

Aneja, K. R., Dhiman, R., Aggarwal, N. K. and Aneja, A. (2014). Emerging preservation techniques for controlling spoilage and pathogenic microorganisms in fruit juices, International Journal of Microbiology 2014: 1-14.

Aničić, N., Gašić, U., Lu, F., Ćirić, A., Ivanov, M., Jevtić, B., Dimitrijević, M., Anđelković, B., Skorić, M., Nestorović Živković, J., Mao, Y., Liu, J., Tang, C., Soković, M., Ye, Y. and Mišić, D. (2021). Antimicrobial and immunomodulating activities of two endemic Nepeta species and their major iridoids isolated from natural sources, Pharmaceuticals 14(5): 414.

Aras, A., Bursal, E. and Dogru, M. (2016). UHPLC-ESI-MS/MS analyses for quantification of phenolic compounds of Nepeta nuda subsp. Iydiae, Journal of Applied Pharmaceutical Science 6(11): 9-13.

Asgarpanah, J., Sarabian, S. and Ziarati, P. (2014). Essential oil of Nepeta genus (Lamiaceae) from Iran: A review, Journal of Essential Oil Research 26(1): 1-12.

Batiha, G. E.-S., Beshbishy, A. M., Ikram, M., Mulla, Z. S., El-Hack, M. E. A., Taha, A. E., Algammal, A. M. and Elewa, Y. H. A. (2020). The pharmacological activity, biochemical properties, and pharmacokinetics of the major natural polyphenolic flavonoid: Quercetin, Foods 9(3): 374. 
CLSI (2015). Methods for Dilution Antimicrobial Susceptibility Tests for Bacteria That Grow Aerobically; Approved Standard, CLSI document M07-A10, $10^{\text {th }}$ edn, Clinical and Laboratory Standards Institute, Wayne, PA.

Daouk, R. K., Dagher, S. M. and Sattout, E. J. (1995). Antifungal activity of the essential oil of Origanum syriacum L., Journal of Food Protection 58(10): 1147-1149.

Dienaitè, L., Pukalskienè, M., Matias, A. A., Pereira, C. V., Pukalskas, A. and Venskutonis, P. R. (2018). Valorization of six Nepeta species by assessing the antioxidant potential, phytochemical composition and bioactivity of their extracts in cell cultures, Journal of Functional Foods 45: 512-522.

Espinel-Ingroff, A. (2001). Comparison of the E-test with the NCCLS M38-P method for antifungal susceptibility testing of common and emerging pathogenic filamentous fungi, Journal of Clinical Microbiology 39(4): 1360-1367.

Fiolet, T., Srour, B., Sellem, L., Kesse-Guyot, E., Allès, B., Méjean, C., Deschasaux, M., Fassier, P., Latino-Martel, P., Beslay, M., Hercberg, S., Lavalette, C., Monteiro, C. A., Julia, C. and Touvier, M. (2018) Consumption of ultra-processed foods and cancer risk: Results from NutriNet-Santé prospective cohort, British Medical Journal 360: k322.

Gašić, U. M., Natić, M. M., Mišić, D. M., Lušić, D. V., Milojković-Opsenica, D. M., Tešić, i. L. and Lušić, D. (2015). Chemical markers for the authentication of unifloral Salvia officinalis L. honey, Journal of Food Composition and Analysis 44: 128-138.

Gayán, E., Serrano, M. J., Monfort, S., Álvarez, I. and Condón, S. (2013) Pasteurization of apple juice contaminated with Escherichia coli by a combined UV-mild temperature treatment, Food and Bioprocess Technology 6(11): 3006-3016.

Gormez, A., Bozari, S., Yanmis, D., Gulluce, M., Agar, G. and Sahin, F. (2013). Antibacterial activity and chemical composition of essential oil obtained from Nepeta nuda against phytopathogenic bacteria, Journal of Essential Oil Research 25(2): 149-153.

Heinz, V., Toepfl, S. and Knorr, D. (2003). Impact of temperature on lethality and energy efficiency of apple juice pasteurization by pulsed electric fields treatment, Innovative Food Science \& Emerging Technologies 4(2): 167-175

Keyser, M., Múller, I. A., Cilliers, F. P., Nel, W. and Gouws, P. A. (2008) Ultraviolet radiation as a non-thermal treatment for the inactivation of microorganisms in fruit juice, Innovative Food Science \& Emerging Technologies 9(3): 348-354.

Kozuharova, E., Benbassat, N. and Getov, I. (2014). Ethnobotanical records of not yet documented therapeutic effects of some popular Bulgarian medicinal plants, Emirates Journal of Food and Agriculture 26(7): 647

Li, Z., Guo, X., Cao, Z., Liu, X., Liao, X., Huang, C., Xu, W., Liu, L. and Yang, P. (2018). New MS network analysis pattern for the rapid identification of constituents from traditional Chinese medicine prescription Lishukang capsules in vitro and in vivo based on UHPLC/Q-TOF-MS, Talanta 189: 606-621.

Magnani, C., Isaac, V. L. B., Correa, M. A. and Salgado, H. R. N. (2014). Caffeic acid: A review of its potential use in medications and cosmetics, Anal. Methods 6(10): 3203-3210.

Mišić, D., Šiler, B., Gašić, U., Avramov, S., Živković, S. Nestorović Živković, J., Milutinović, M. and Tešić, i. (2015). Simultaneous UHPLC/DAD/(+/-)HESI-MS/MS analysis of phenolic acids and nepetalactones in methanol extracts of Nepeta species: A possible application in chemotaxonomic studies, Phytochemical Analysis 26(1): 72-85.

Nadeem, M., Imran, M., Aslam Gondal, T., Imran, A., Shahbaz, M. Muhammad Amir, R., Wasim Sajid, M., Batool Qaisrani, T., Atif, M., Hussain, G., Salehi, B., Adrian Ostrander, E., Martorell, M., Sharifi-Rad, J., C. Cho, W. and Martins, N. (2019). Therapeutic potential of rosmarinic acid: A comprehensive review, Applied Sciences 9(15): 3139.

Nargis Jamila (2011). Secondary metabolites from Nepeta juncea, African Journal of Biotechnology 10(77): 17884-17886.

Pacifico, S., Galasso, S., Piccolella, S., Kretschmer, N., Pan, S.-P., Marciano, S., Bauer, R. and Monaco, P. (2015). Seasonal variation in phenolic composition and antioxidant and anti-inflammatory activities of Calamintha nepeta (L.) Savi, Food Research International 69: 121132.

Reis, F. S., Stojković, D., Soković, M., Glamočlija, J., Ćirić, A., Barros, L. and Ferreira, I. C. (2012). Chemical characterization of Agaricus bohusii, antioxidant potential and antifungal preserving properties when incorporated in cream cheese, Food Research International 48(2): 620 626.

Salehi, B., Valussi, M., Jugran, A. K., Martorell, M., Ramírez-Alarcón, K. Stojanović-Radić, Z. Z., Antolak, H., Kręgiel, D., Mileski, K. S., SharifiRad, M., Setzer, W. N., Cádiz-Gurrea, M. d. I. L., Segura-Carretero, A., Şener, B. and Sharifi-Rad, J. (2018). Nepeta species: From farm to food applications and phytotherapy, Trends in Food Science \& Technology 80: 104-122.

Sharma, A., Cooper, R., Bhardwaj, G. and Cannoo, D. S. (2021). The genus Nepeta: Traditional uses, phytochemicals and pharmacological properties, Journal of Ethnopharmacology 268: 113679

Smiljković, M., Dias, M. I., Stojković, D., Barros, L., Bukvički, D., Ferreira, I. C. F. R. and Soković, M. (2018). Characterization of phenolic compounds in tincture of edible Nepeta nuda: development of antimicrobial mouthwash, Food \& Function 9(10): 5417-5425.

Snook, M. E., Blum, M. S., Whitman, D. W., Arrendale, R. F., Costello, C. E. and Harwood, J. S. (1993). Caffeoyltartronic acid from catnip (Nepeta cataria): A precursor for catechol in lubber grasshopper (Romalea guttata) defensive secretions, Journal of Chemical Ecology 19(9): 19571966.

Süntar, I., Nabavi, S. M., Barreca, D., Fischer, N. and Efferth, T. (2018) Pharmacological and chemical features of Nepeta L. genus: Its impor tance as a therapeutic agent, Phytotherapy Research 32(2): 185-198.

Takeda, Y., Morimoto, Y., Matsumoto, T., Honda, G., Tabata, M., Fujita T., Otsuka, H., Sezik, E. and Yesilada, E. (1995). Nepetanudoside, an iridoid glucoside with an unusual stereostructure from Nepeta nuda ssp. albiflora, Journal of Natural Products 58(8): 1217-1221.

Takeda, Y., Yagi, T., Matsumoto, T., Honda, G., Tabata, M., Fujita, T., Shingu, T., Otsuka, H., Sezik, E. and Yesilada, E. (1996). Nepetanudosides and iridoid glucosides having novel stereochemistry from Nepeta nuda ssp. albiflora, Phytochemistry 42(4): 1085-1088.

Tsukatani, T., Suenaga, H., Shiga, M., Noguchi, K., Ishiyama, M., Ezoe, T. and Matsumoto, K. (2012). Comparison of the WST-8 colorimetric method and the CLSI broth microdilution method for susceptibility testing against drug-resistant bacteria, Journal of Microbiological Methods 90(3): 160-166

Vasić, V., Gašić, U., Stanković, D., Lušić, D., Vukić-Lušić, D., MilojkovićOpsenica, D., Tešić, i. and Trifković, J. (2019). Towards better quality criteria of European honeydew honey: Phenolic profile and antioxidant capacity, Food Chemistry 274: 629-641.

Wareing, P. and Davenport, R. R. (2004). Microbiology of soft drinks and fruit juices, in P. R. Ashurst (ed.), Chemistry and technology of soft drinks and fruit juices, Blackwell Publishing Ltd, Oxford, UK, pp. 279299. 